\title{
Article \\ The Evaluation of Temporal and Spatial Trends of Global Warming and Extreme Ocean Surface Temperatures: A Case Study of Canada
}

\author{
Yameng Wang 1,+(D), Apurbo Sarkar ${ }^{1,+}$, Ahmed Khairul Hasan ${ }^{2}$, Yingdong Tian ${ }^{3}$, Qian $\mathrm{Wu}^{1}$, \\ Md. Shakhawat Hossain ${ }^{4}$ and Feng Wei ${ }^{1, *}$
}

check for updates

Citation: Wang, Y.; Sarkar, A.; Hasan, A.K.; Tian, Y.; Wu, Q.; Hossain, M.S.; Wei, F. The Evaluation of Temporal and Spatial Trends of Global Warming and Extreme Ocean Surface Temperatures: A Case Study of Canada. ISPRS Int. J. Geo-Inf. 2022, 11, 21. https://doi.org/10.3390/ ijgi11010021

Academic Editors: Matteo Gentilucci, Marco Materazzi,

Margherita Bufalini,

Gilberto Pambianchi and

Wolfgang Kainz

Received: 31 October 2021

Accepted: 27 December 2021

Published: 30 December 2021

Publisher's Note: MDPI stays neutral with regard to jurisdictional claims in published maps and institutional affiliations.

Copyright: (c) 2021 by the authors Licensee MDPI, Basel, Switzerland. This article is an open access article distributed under the terms and conditions of the Creative Commons Attribution (CC BY) license (https:// creativecommons.org/licenses/by/ $4.0 /)$
1 College of Economics and Management, Northwest Agriculture and Forestry University, Xianyang 712100, China; wym@nwafu.edu.cn (Y.W.); apurbo@nwafu.edu.cn (A.S.); wuqian1803@nwafu.edu.cn (Q.W.)

2 Department of Agronomy, Bangladesh Agricultural University, Mymensingh 2202, Bangladesh; akhasan@bau.edu.bd

3 College of Economics and Management, Nanjing University of Science and Technology, Nanjing 210094, China; tianyingdong@njust.edu.cn

4 College of Agronomy, Northwest Agriculture and Forestry University, Xianyang 712100, China; shakhawat@nwafu.edu.cn

* Correspondence: weifeng@nwsuaf.edu.cn; Tel.: +86-1568-4343-120

$+\quad$ These authors contributed equally to this work.

\begin{abstract}
In recent years, extreme weather has frequently occurred worldwide and caused significant disasters, including large-scale forest fires, rare heat waves, heavy rains, floods, and tornadoes. Those have caused unprecedented losses of human lives and property in some countries, affecting the livelihoods of many people. Climate change and natural disasters are the two hotspots of scientific research today, and there is a certain degree of correlation between the two. Although countries worldwide have long known about climate change and its threats to human existence and have been discussing countermeasures, they have still not been able to carry out concerted and practical actions. The study takes Canada as an example, and selects six representative provinces to evaluate the temporal change characteristics of extreme temperature at different sites. We use MATLAB software to perform multiple linear regression, linear fitting methods, and Pearson correlation analysis to analyze spatial changes and time-space trends. The method studies the relationship between the emergence of extreme weather and climate change and uses the evolutionary game theory to explore whether there is any contradiction between global warming and extreme local cold. The study found: (i) The maximum temperature of most provinces in Canada will be constantly higher, and the minimum temperature will be lower. Generally speaking, the average temperature of each year is slowly decreasing. (ii) The average temperature data of British Columbia (Eastern Pacific) and Quebec (West Atlantic) show that ocean temperature has a specific effect on land temperature in surrounding areas. (iii) Pearson correlation analysis shows that the emergence of extreme weather is closely related to climate change. (iv) The evolution path of the two-party game shows that global warming and the occurrence of extreme local cold are not contradictory. Under the conditions, there is a certain degree of synchronization between the two, interacting and influencing each other.
\end{abstract}

Keywords: extreme weather; global warming; temporal and spatial trends; Pearson correlation analysis; evolutionary game; Canada

\section{Introduction}

In recent years, extreme weather has frequently occurred worldwide and caused significant disasters, including widespread forest fires, rare heat waves, heavy rains, floods, and tornadoes [1,2]. It has caused unprecedented losses of human lives and property in some countries and affects many people's livelihoods [3,4]. Many scientists believe that global 
warming is the leading cause of extreme weather. Global warming is causing a series of climate changes that threaten human survival, such as melting glaciers, shrinking cryosphere, and frequent extreme events [5]. According to the statistics of the Intergovernmental Panel on Climate Change (IPCC) on meteorological observation data in the world in the last hundred years from 1906 to 2005, the global average surface temperature (SAT) increased by $0.74{ }^{\circ} \mathrm{C}$. At the end of this century, the global average surface temperature will rise by 1.1-6.4 ${ }^{\circ} \mathrm{C}$, and the sea level will rise by $0.18-0.59 \mathrm{~m}$ [6-8]. In October 2018, the "Special Report on Global Warming" issued by the IPCC pointed out that if climate warming continues at the current rate, it is estimated that the global temperature increase may reach $1.5^{\circ} \mathrm{C}$ as early as 2030. After 2030, the Earth will face a relatively challenging climate and the trends of changes in the global climate exacerbate climate hazards and amplify the risk of extreme weather disasters $[9,10]$. Increases of air and water temperatures lead to rising sea levels, supercharged storms and higher wind speeds, more intense and prolonged droughts and wildfire seasons, heavier precipitation, and flooding [11]. Such events occur frequently as people burn fossil fuels, such as oil and coal, or cut down forests and burn them; these activities will produce a lot of carbon dioxide and other major greenhouse gases. In 2019, about 43.1 billion tons of $\mathrm{CO}_{2}$ from human activities were emitted into the atmosphere [12]. These greenhouse gases have high transmittance for visible light from solar radiation and high absorption for long-wave radiation emitted by the Earth, which can powerfully absorb the infrared radiation, leading to the rise of earth temperature, namely, the greenhouse effect [13]. When the greenhouse effect continues to accumulate, the energy absorption and emission of the Earth's air system is unbalanced, and the energy is accumulated in the Earth's air system, which leads to temperature rise and global warming [14,15]. One of the consequences of global warming is that precipitation will be more concentrated, and with more extreme weather, there will be more periods of little precipitation or no precipitation [16].

Canada has abundant energy resources, is a developed country with modern industry and scientific and technological level, is sparsely populated, and has a high forest coverage rate [17]. Canada's development of clean technology is outstanding globally, and it has natural advantages in dealing with climate change. However, due to its growing population and the dependence of economic development on energy, Canada is now one of the world's largest emitters of greenhouse gases per capita, with a per capita carbon dioxide emission of 16.85 tons, causing severe pollution [18]. According to the greenhouse gas emission data released by British risk assessment company Maplecroft (http:/ / www.maplecroft.com, accessed on 27 July 2021), Canada's annual greenhouse gas emission is 610 million tons, ranking seventh in the world, after China (6 billion tons/year), the United States (5.9 billion tons/year), Russia (1.7 billion tons/year), India (1.29 billion tons/year), and Japan (1.247 billion tons/year). The rate of climate warming in Canada is twice that of other parts of the world, and the rate of warming in Northern Canada is more than twice that of the global average ("Canadian Climate Change Report", 2019). In June 2021, relatively high temperatures occurred in many areas of Canada, and temperatures in more than 40 places in British Columbia broke records [19]. On 28 June, the temperature in British Columbia reached 47.5 degrees Celsius, which has already broken the highest temperature in Canada since meteorological records were recorded. On 29 June, the temperature reached a new high of 49.5 degrees Celsius, once called the Genesis High Temperature in Canada [20].

Canada has typical global warming climate characteristics and extreme weather. Therefore, the article takes Canada as the research object. While analyzing the temporal and spatial trends of Canada's global warming, the Pearson correlation analysis method is used to study the relationship between the emergence of extreme weather and climate change. This article aims to further understand the factors that affect climate change, explain the occurrence of extreme weather phenomena, and find and verify the impact of climate change. In order to increase their awareness of climate change, people should start from the present and from themselves, while at the same time urging decision-makers to formulate policies to deal with climate change quickly. 
Ye et al. [21] pointed out that the interdecadal scale is a significant time scale. The disturbance is superimposed on the long-term change trend and essential background for monthly-season-interannual climate change and prediction with a shorter time scale. Since late last century, interdecadal climate variability has gradually become the focus of international climate change research, and international research projects have also taken interdecadal climate change and prediction as to their primary research goal. When researching the interdecadal variability of climate, it was found that the interdecadal variability exists in temperature changes. In addition to temperature, precipitation, sea temperature, and atmospheric circulation fields also have noticeable interdecadal changes [22] Nakamura et al. used sea surface temperature (SST) data to find significant interdecadal variability in winter sea temperature in the North Pacific and preliminarily explained the physical mechanism of its formation [23,24]. The above research results show that various meteorological elements in the climate system exhibit significant interdecadal changes characteristics. In-depth research on the physical mechanism of interdecadal climate variability began in the late 1980s when oceanic general circulation models (OGCMs) and coupled ocean-atmosphere models (CGCMs) were widely used. Weaver et al. [25] used a highly simplified oceanic general circulation model under surface boundary conditions to first analyze the interdecadal variability of the Atlantic thermohaline circulation (THC). They pointed out that it is a possible mechanism for forming interdecadal climate variability.

In 1994, Latif et al. [26] proposed the physical mechanism of the interdecadal variability of the North Pacific by studying the upper ocean wind-driven circulation in the CGCM and its interaction with the atmosphere. With the development of science and the continuous improvement of social demand, forecasting climate change for the next few decades is becoming one of the top research tasks [27]. With the gradual improvement of the understanding of the members of the climate system and their interactions, the development of climate models has made significant progress, but the current model's ability to predict climate change on the time scale of the next few decades is still in its infancy. Because the climate predictions on the interdecadal time scale are essentially different from those on the centennial scale, the climate change on the centennial-scale is mainly affected by artificial forcing, and the interdecadal climate change is affected by the combination of natural internal variability and artificial forcing, especially climate change on a regional scale. Hawkins et al. [28] further found that for the next 10 to 30 years of climate change, the uncertainty of natural internal variability will be far greater than the uncertainty of man-made forcing. Therefore, natural internal variability is significant for the prediction of interdecadal climate change, and it is also a scientific problem that needs to be faced and challenged in the field of climate. Though vibrant literature can be traced to trigger global warming and ocean temperature, most of them do not consider these two phenomena within the same framework. Therefore the study intends to fill the knowledge gap by exploring global warming and atmospheric temperature changes in an integrated framework. Broadly, the study aims to explain extreme weather phenomena by further understanding the factors affecting climate change. We analyze the temporal and spatial variation trend of global warming in Canada and study the relationship between extreme weather and climate change by Pearson correlation analysis based on factors such as heat absorption and heat dissipation. We seek to find and verify the factors that affect climate change in order to enhance people's awareness of climate change, and urge decision-makers to formulate policies to deal with climate change quickly while starting from now and starting from themselves. The most significant innovation of the study article is to introduce the evolutionary game method into the relationship between global warming and extreme cold in local areas. The evolutionary game method is used to study whether there is a contradiction between global warming and the occurrence of extreme local cold with the probability changes of global warming and extreme local cold. The probability change of global warming and extreme local cold is used to study a contradiction between global warming and extreme local cold. As the study analyses the gradual stability and evolutionary stability strategies of extreme events, it can provide a reference for other countries 
to recognize the synchronization and interaction between the global warming trend and the local extreme cold phenomenon. At the same time, it also fills the gaps in this type of research in academia.

\section{Materials and Methods}

\subsection{Research Object and Data Source}

The article mainly studies the relationship between global warming and natural disasters. In this study, global warming has been indicated by temperature rise. In the study, we propose that temperature rise will cause global sea level to rise, and atmospheric circulation will undergo significant changes, leading to extreme weather phenomena. The temporal and spatial variation trend of temperature in the region was excavated from the historical data of weather changes in Canada. Due to the difficulty of data collection, the historical data of weather changes in six provinces of Canada, namely Columbia, Alberta, Saskatchewan, Manitoba, Ontario, and Quebec (from $45^{\circ} \mathrm{N}$ to $60^{\circ} \mathrm{N}$, from the eastern coast of the Pacific to the western coast of the Atlantic) were selected for analysis. The climate data are extracted from Canadian meteorological stations' daily maximum temperature and minimum temperature data from 1961 to 2019. After eliminating the stations with too much data missing, the fitting equation near two stations is used to obtain the unknown data through the known data to supplement the missing data.

\subsection{Multiple Linear Regression}

When performing multiple linear regressions, each year's daily maximum, minimum, and average temperature data are weighted and averaged to obtain the maximum, minimum, and average temperature of each year. Moreover, we use MATLAB software to linearly fit the annual maximum temperature, minimum temperature, and average temperature.

The article does not treat extreme conditions as being above normal temperature in summer and below the normal temperature in winter. It mainly analyzes the relationship between the emergence of extreme weather and climate change by analyzing the correlation between seven variables. The seven variables are (i) the highest daily temperature in the year, (ii) the lowest daily temperature in the year, (iii) the highest annual temperature (weighted average of daily data), (iv) the lowest annual temperature (weighted average of daily data), (v) the annual average temperature (weighted daily data average), (vi) the highest precipitation in a year and (vii) the highest snowfall in a year.

The weighted average method is relative to the simple average value. The reason for using weighting (adding another variable to the calculation process) is to eliminate the inaccuracy of the simple average, and the weighted average is closer to the truth. The principle is that when specific numbers in a set of data appear several times, then the representation of their average number changes to a certain extent. The weighted average size depends not only on the value of each unit (variable value) in the population but also on each value's number of occurrences (frequency). Since the number of occurrences of each value weighs its influence on the average, it is called a weight. Because the weighted average is the calculation of the average based on the different weights, it is also called the weighted average. When choosing the weighted average, this article refers to the practice in existing research papers. In the statistics about the year, the weighted average of days is used.

In practical economic problems, a variable is often affected by multiple variables. The general form of the multivariable linear regression model is:

$$
Y_{\mathrm{i}}=\beta_{0}+\beta_{1} X_{1 i}+\beta_{2} X_{2 i}+\ldots+\beta_{k} X_{k i}+\mu_{\mathrm{i}}, \mathrm{i}=1,2,3, \ldots, \mathrm{n}
$$


In which $k$ is the number of explanatory variables, and $\beta_{j}(j=1,2, \ldots, k)$ is called the regression coefficient. The above equation is also called the random expression of the overall regression function. Its non-random expression is

$$
E\left(Y \mid X_{1 i}, X_{2 i}, \ldots, X_{k i}\right)=\beta_{0}+\beta_{1} X_{1 i}+\beta_{2} X_{2 i}+\ldots+\beta_{k} X_{k i}
$$

$\beta_{j}$ is also called the partial regression coefficient. The extreme temperature value is defined as firstly, the daily maximum (low) temperature data of each station from 1980 to 2019 are arranged in descending order, and the fifth (95) percentile value is defined as the extreme high (low) value of the maximum (minimum) temperature of the station in that year. The time series of extreme temperature values were established using six site data. Six provinces have been selected by considering climate, topography, and geomorphology characteristics. The average values of site data in each region were calculated, representing the highly alleviated value of the highest temperature and the extremely high value of the lowest temperature in the region.

\subsection{Pearson Analysis of the Relationship}

Correlation analysis is a commonly used statistical algorithm to explore the correlation between two random variables in the same position [29]. This method can study the relationship between extreme weather and climate change [30]. The correlation coefficient value is used to show how close the relationship is and the associated steps as follows:

Step 1: Pearson correlation coefficient describes the linear correlation between the two random variables. If there are two groups of random variables: $X_{1}, X_{2}, X_{3}, \ldots, X_{n}$ and $Y_{1}$, $Y_{2}, Y_{3}, \ldots, Y_{n}$. Where, $n$ is the number of samples, then the Pearson correlation coefficient can be calculated by the following formula:

$$
r=\frac{\sum_{i=1}^{n}\left(x_{i}-\bar{x}\right)\left(y_{i}-\bar{y}\right)}{\sqrt{\sum_{i=1}^{n}\left(x_{i}-\bar{x}\right)^{2}} \sqrt{\sum_{i=1}^{n}\left(y_{i}-\bar{y}\right)^{2}}}
$$

The absolute value of the correlation coefficient varies from 0 to 1 , and the more significant the $|r|$, the better the correlation. If $r$ is more significant than zero, the two random variables are positively correlated. If $r$ is less than zero, this indicates a negative correlation. The second step is to test whether the correlation between the two is significant, generally using the $F$ test. $F$ test is a hypothesis test to test whether there is a significant difference in the overall variance between the two samples. In the case of unknown overall variance, it is assumed that $R S S_{r}$ and $R S S_{N}$ are the variances from two independent normal populations, respectively. Then, the formula of the statistical $F$ test is shown in Equation (4):

$$
F=\frac{\left(R S S_{r}-R S S_{N}\right) / m}{R S S_{N} /(N-2 m)}
$$

where $R S S_{r}$ is the sum of squares of constrained residuals, $R S S_{N}$ is the sum of squares of unconstrained residuals, $N$ is the sample size, and $m$ is the maximum lag order.

\subsection{Evolutionary Game Method}

Global warming is a disastrous result brought about by excessive production behavior and industrialization in recent years, while extreme local cold is an occasional weather change with a certain randomness. Is it "contradictory" that global warming and extreme local cold occur simultaneously? Will the two affect each other as time goes by, and what kind of influence will it have? In order to solve this problem, the study uses the evolutionary game method for analysis as recommended by Qiao and Yin [31]. The evolutionary game was first applied to the study of conflict and cooperative behavior in biological evolution, and in recent years it has also been applied and studied in natural science fields such as environment and climate change [32]. 
According to the evolutionary game method (see Weibull [33] for more details), the global scope and local scope can be regarded as two central bodies in the evolutionary game, in which global warming and constant warming, the extreme cold phenomenon in the local scope, and no extreme cold phenomenon are the two main trends. The evolutionary game method is used to study the contradiction between global warming and local extreme cold phenomenon. The two subjects are represented as global (G) and local (L). At the same time, the global scope and local as the subjects have their strategies, namely, the two strategies of global $(\mathrm{G})$ warming and constant, and the two strategies of local (L) extreme cold and normal. The probability of global warming is $x$, constant global warming is $1-x$, the probability of extreme local cold is $y$, and the probability of local weather normal is $1-\mathrm{y}$.

The article regards the global and local scopes as the two main players in the evolutionary game. Among them, global warming and non-warming, local extreme cold and no extreme cold are the two main strategies (trends). Suppose the number of people affected by global warming is $n_{1}$, the harm of global warming to the number of people per unit $h_{1}$, the number of people affected by extreme local cold $n_{2}$, the harm of extreme local cold to the number of people per unit $h_{2}$, the contribution of extreme local cold to mitigating global warming $a$, and the contribution of global warming to mitigating local extreme cold $b$. Then, global and local game strategies and benefits are shown in Table 1:

Table 1. Main player strategy and payoff matrix of global and local games.

\begin{tabular}{cccc}
\hline \multirow{2}{*}{ Main Strategy and Benefits } & \multicolumn{2}{c}{ Local (L) } \\
& & Extremely Cold y & Normal 1 - y \\
\hline Global & Warming $\mathrm{x}$ & $\left(\mathrm{a}-h_{1} n_{1}, \mathrm{~b}-h_{2} n_{2}\right)$ & $\left(-h_{1} n_{1},\right)$ \\
$(\mathrm{G})$ & Non-warming $1-\mathrm{x}$ & $\left(,-h_{2} n_{2}\right)$ & $()$, \\
\hline
\end{tabular}

In addition, the physical interpretation of time is a collection (rounds) of the number of games. For example, in the picture, each $\mathrm{x},{ }^{*}$, and + represents a game between the different strategies of the two parties (+++ represents 3 games, ++++ represents 4 games). The expected return and average return of global $(\mathrm{G})$ warming and non-warming are $U_{11}$, $U_{12}$ and $U_{1}$, respectively. The formulas of the return are shown in Equations (5)-(7):

$$
\begin{gathered}
U_{11}=\mathrm{y}\left(a-h_{1} n_{1}\right)+(1-y)\left(-h_{1} n_{1}\right) \\
U_{12}=0 \\
U_{1}=\mathrm{x} U_{11}+(1-\mathrm{x}) U_{12}=\mathrm{xy}\left(\mathrm{a}-h_{1} n_{1}\right)+\mathrm{x}(1-y)\left(-h_{1} n_{1}\right)
\end{gathered}
$$

The expected and average returns of local (L) extreme cold occurrence and normal weather are $U_{21}, U_{22}$ and $U_{2}$, respectively. The formulas of the returns are as follows:

$$
\begin{gathered}
U_{21}=\mathrm{x}\left(\mathrm{b}-h_{2} n_{2}\right)+(1-x)\left(-h_{2} n_{2}\right) \\
U_{21}=0 \\
U_{2}=\mathrm{y} U_{21}+(1-\mathrm{y}) U_{22}=\mathrm{yx}\left(\mathrm{b}-h_{2} n_{2}\right)+(1-y) x\left(-h_{2} n_{2}\right)
\end{gathered}
$$

According to the Malthusian dynamic equation, the growth rate of selecting a strategy in a group is equal to its relative fitness. As long as the fitness of the individual adopting the strategy is higher than that of the group, the proportion of members selecting the strategy will increase. According to the dynamic replication formula of the evolutionary game, the dynamic replication equation of the dynamic system can be obtained, as shown in Equation (11), where $G(\mathrm{x})$ is the dynamic replication equation of global strategy selection and $L(\mathrm{y})$ is the dynamic replication equation of local strategy selection.

$$
\left\{\begin{array}{l}
G(x)=\mathrm{x}\left(U_{11}-U_{1}\right)=\mathrm{x}(1-\mathrm{x})\left(\mathrm{ya}-h_{1} n_{1}\right) \\
L(y)=\mathrm{y}\left(U_{21}-U_{2}\right)=\mathrm{y}(1-\mathrm{y})\left(\mathrm{xb}-h_{2} n_{2}\right)
\end{array}\right.
$$


A two-dimensional dynamical system consisting of replicated dynamic equations $G(\mathrm{x})=0$, with $L(\mathrm{y})=0$, then, five equilibrium points can be obtained. Those are $E_{1}(0,0)$, $E_{2}(0,1), E_{3}(1,0), E_{4}(1,1)$, with $E_{5}\left(\frac{h_{2} n_{2}}{\mathrm{~b}}, \frac{h_{1} n_{1}}{\mathrm{a}}\right)$.

According to the two-dimensional dynamic system composed of the above replicated dynamic equation, the Jacobian matrix can be constructed, as shown in Equation (12):

$$
J=\left[\begin{array}{ll}
F_{11} & F_{12} \\
F_{21} & F_{22}
\end{array}\right]
$$

Among them: $F_{11}=\frac{\vartheta G(x)}{\vartheta x}=(1-2 x)\left(y a-h_{1} n_{1}\right), F_{12}=\frac{\vartheta G(x)}{\vartheta \mathrm{y}}=\mathrm{x}(1-x) a, F_{21}=$ $\frac{\vartheta L(\mathrm{y})}{\vartheta \mathrm{x}}=\mathrm{y}(1-\mathrm{y}) b$ and $F_{22}=\frac{\vartheta L(\mathrm{y})}{\vartheta \mathrm{y}}=(1-2 \mathrm{y})\left(\mathrm{xb}-h_{2} n_{2}\right)$.

According to the discriminant method of the stability of the equilibrium point, the determinant Det J and trace Tr J of the Jacobian matrix can be used for discrimination. That is, when Det $\mathrm{J}>0$ and $\operatorname{Tr} \mathrm{J}<0$, the equilibrium point is an evolutionary stable point. When Det $\mathrm{J}<0$ the equilibrium point is a saddle point. In other cases, the equilibrium point is unstable. The stability criterion of equilibrium points is shown in Table 2:

Table 2. Stability discrimination of equilibrium points.

\begin{tabular}{ccccc}
\hline Balance Point & Det J & Tr J & Steadiness & Steady-State Conditions \\
\hline$E_{1}(0,0)$ & $>0$ & $<0$ & Stationary point & \\
$E_{2}(0,1)$ & $>0$ & $>0$ & Instability point & $\left(\mathrm{a}-h_{1} n_{1}\right)>0$ \\
& $<0$ & & saddle point & $\left(\mathrm{a}-h_{1} n_{1}\right)<0$ \\
$E_{3}(1,0)$ & $>0$ & $>0$ & Instability point & $\left(\mathrm{b}-h_{2} n_{2}\right)>0$ \\
$E_{4}(1,1)$ & $<0$ & & saddle point & $\left(\mathrm{b}-h_{2} n_{2}\right)<0$ \\
$E_{5}\left(\frac{\mathrm{h}_{2} \mathrm{n}_{2}}{\mathrm{~b}}, \frac{\mathrm{h}_{1} \mathrm{n}_{1}}{\mathrm{a}}\right)$ & $>0$ & $<0$ & stationary point & $\left(\mathrm{a}-h_{1} n_{1}\right)\left(\mathrm{b}-h_{2} n_{2}\right)>0$ \\
& $<0$ & $=0$ & saddle point & $\left(\mathrm{a}-h_{1} n_{1}+\mathrm{b}-h_{2} n_{2}\right)>0$ \\
& & & &
\end{tabular}

$E_{1}(0,0)$ and $E_{4}(1,1)$ can all become evolutionary equilibrium points. Here we only analyze the evolution equilibrium under $\left(\mathrm{a}-h_{1} n_{1}\right)>0$ and $\left(\mathrm{b}-h_{2} n_{2}\right)>0$ conditions (Set the relevant parameter value to $\left.\mathrm{a}=10, h_{1}=2, n_{1}=4, \mathrm{~b}=5, h_{2}=1, n_{2}=2\right)$. MATLAB software draws the dynamic phase diagram, as shown in Figure 1. The horizontal axis represents the probability of global warming, and the vertical axis represents the probability of extreme local cold. In the evolution diagram of global and local games, $E_{1}(0,0)$ and $E_{4}(1,1)$ are evolutionary equilibrium points.

In order to more directly observe whether there is a contradiction between global warming and extreme local cold, the probability of global warming and extreme local cold is numerically simulated. The first is the evolution path of both sides when different probability values are set for global warming and extreme local cold. The second is the evolution path of the two sides when setting different parameter values (a and $b$ ) in the model.

The exact step outlined in the study has been as follows: (i) first, the historical data of the weather across Canada is downloaded from the website:

https:/ / climate.weather.gc.ca/historical_data/search_historic_data_e.html (accessed on 27 August 2021). (ii) Second, taking each province as the research object, the graphs are all overtime trend scatter plots, and multiple linear regressions are used for fitting (now the previous six scatter plots have been merged into one graph, which has been streamlined). Furthermore, a t-test for individual parameter estimation, an F-test for the overall model estimation, and a DW test were also done. The test results are all significant. Since the main research focus of this article is not here, and the original article is long, it is not included in the thesis. (iii) Third, Pearson's correlation coefficient is used to describe the degree of linear correlation between two random variables, and to conduct a significant test for the correlation between the two. The study selected data from Alberta and Saskatchewan for verification, using the minimum daily temperature and daily snowfall as representatives 
of extreme cold weather. The annual average temperature and annual snowfall data are used to represent climate change. (iv) Fourth, the evolutionary game analysis did not use specific actual data. Instead, it has been used as a theoretical basis. The global and local scope are the two central bodies in the evolutionary game. The two main changing trends are (i) global warming and non-warming, and (ii) local extreme cold phenomenon and no extreme cold phenomenon. We use the evolutionary game method to study whether there is a contradiction between global warming and the occurrence of extreme local cold with the probability changes of global warming and extreme local cold. The selected two subjects are global (G) and local (L). At the same time, the global scope and the local as the subject have their specific strategies. Where two strategies have derived global $(G)$ aspects, namely (i) warming and (ii) non-warming, local (L) also has two strategies, namely (i) extreme cold and (ii) normal. The probability of global warming is $x$, the probability of global non-warming is $1-x$, the probability of extreme cold is $y$, and the probability of normal is $1-y$. Moreover, we construct the income function of the global scope and the local scope. We construct the Jacobian matrix based on the dynamic replication equation to analyze the evolutionary stability point.

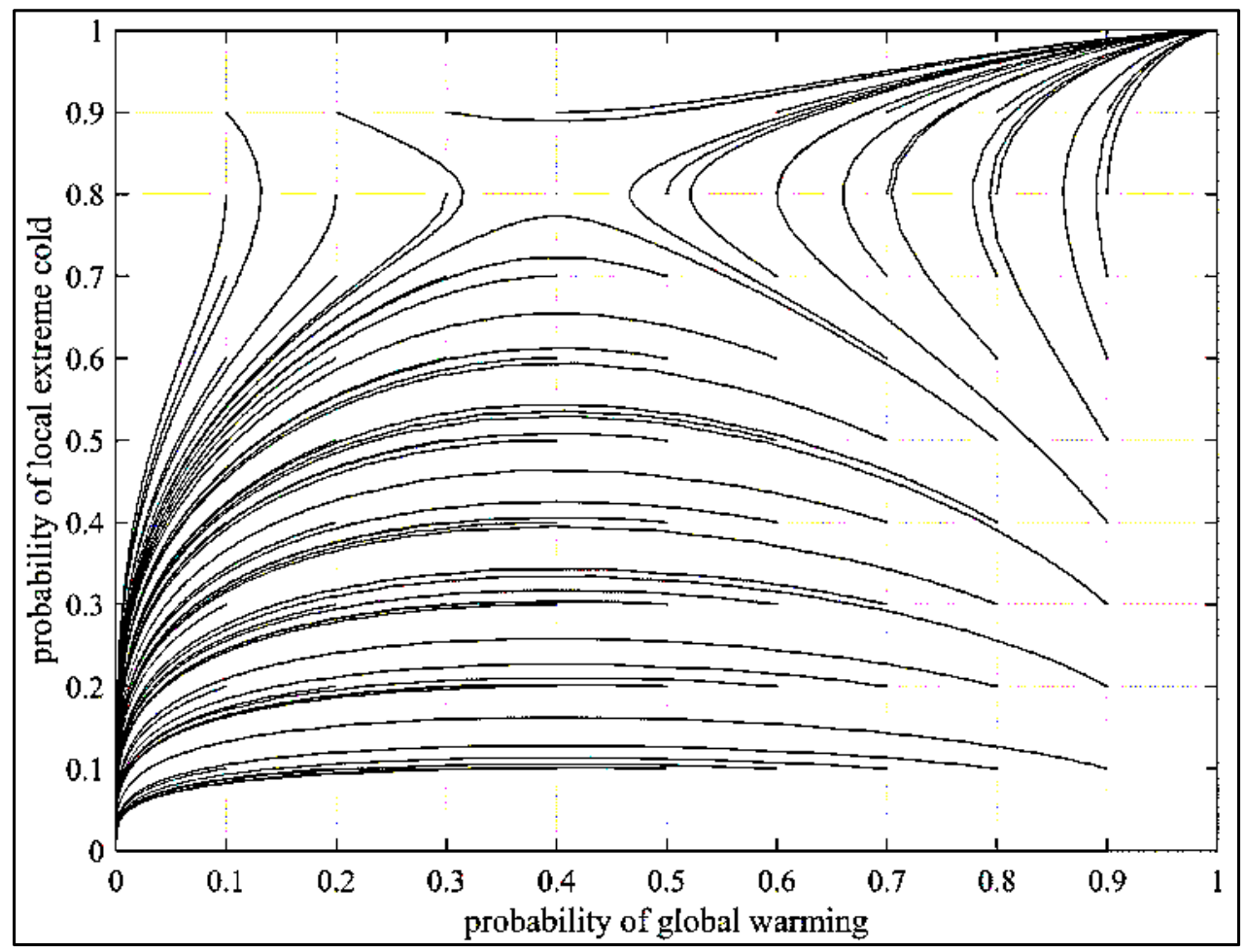

Figure 1. Evolution of global warming and local extreme cold game.

\section{Results}

\subsection{Temporal and Spatial Variation Trend of Temperature in Different Regions of Canada 3.1.1. Statistical Description}

The statistical description of the data, including the time variation trends of maximum temperature, minimum temperature, and the average temperature in six Canadian provinces (stations), are shown in Table 3. The maximum and minimum temperatures in British Columbia (stations) and Alberta (stations) rise and fall, but the average temperature is downward. Maximum, minimum, and mean temperatures in Saskatchewan (site) and Quebec (site) showed an increasing trend. Maximum, minimum, and average temperatures in Manitoba and Ontario showed a decreasing trend. Based on the weighted average of daily temperature data of six Canadian provinces (sites) over the years, the maximum, minimum, and average temperatures of each province (site) can be obtained, as shown in Table 4. In British Columbia and Ontario, it can be seen that maximum temperature, 
minimum temperature, and an average temperature are above $0{ }^{\circ} \mathrm{C}$. Seemingly, for Manitoba, the maximum temperature, minimum temperature, and average temperature are the lowest in six provinces. Figure 2 showed the study sites.

Table 3. Temporal trends of temperatures in six Canadian provinces (sites).

\begin{tabular}{cccc}
\hline Province (Station) & Max Temp & Min Temp & Mean Temp \\
\hline 1. British Columbia (station): 1980-1987 & rise & decline & decline \\
2. Alberta (site): 1986-2019 & decline & rise & decline \\
3. Saskatchewan (site): 1980-2019 & rise & rise & rise \\
4. Manitoba (station): $1961-1968$ & decline & decline & decline \\
5. Ontario (site): 1971-1977 & decline & decline & decline \\
6. Quebec (station): $1992-2019$ & rise & rise & rise \\
\hline
\end{tabular}

Table 4. Temperatures in the six Canadian provinces (sites) over the years.

\begin{tabular}{cccc}
\hline Province (Station) & Max Temp & Min Temp & Mean Temp \\
\hline 1. British Columbia (station): $1980-1987$ & $14{ }^{\circ} \mathrm{C}$ & $6.2^{\circ} \mathrm{C}$ & $10.1^{\circ} \mathrm{C}$ \\
2. Alberta (site): 1986-2019 & $10^{\circ} \mathrm{C}$ & $-2.4^{\circ} \mathrm{C}$ & $3.8^{\circ} \mathrm{C}$ \\
3. Saskatchewan (site): $1980-2019$ & $9.3^{\circ} \mathrm{C}$ & $-2.8^{\circ} \mathrm{C}$ & $3.3^{\circ} \mathrm{C}$ \\
4. Manitoba (station): $1961-1968$ & $8.1{ }^{\circ} \mathrm{C}$ & $-3.7^{\circ} \mathrm{C}$ & $2.2^{\circ} \mathrm{C}$ \\
5. Ontario (site): $1971-1977$ & $11.2^{\circ} \mathrm{C}$ & $3.8^{\circ} \mathrm{C}$ & $7.5^{\circ} \mathrm{C}$ \\
6. Quebec (station): $1992-2019$ & $9.9^{\circ} \mathrm{C}$ & $-0.1^{\circ} \mathrm{C}$ & $5{ }^{\circ} \mathrm{C}$ \\
\hline
\end{tabular}

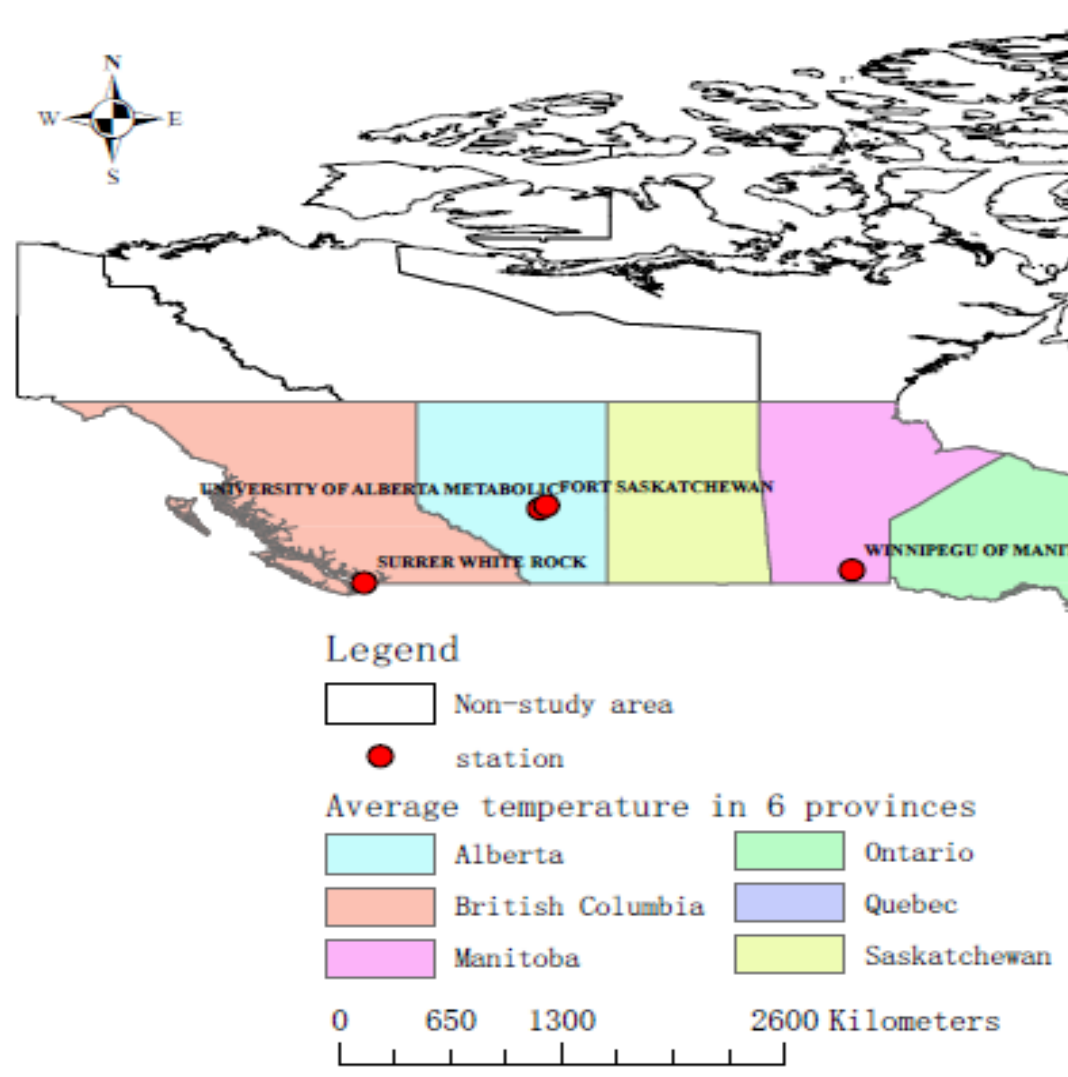

Figure 2. Observation sites in Canadian provinces.

\subsubsection{Trends in Time and Space}

Figure 3a shows the scatter plot and linear fitting of the temperature trend over time in British Columbia (Surrey White Rock site) from 1980 to 1987, mainly by the weighted average of the daily maximum, minimum. Average temperature data in each year are used 
to obtain the annual maximum, minimum, and average temperature. In order to facilitate the fitting, the initial year was set as 1 . The linear fitting equation of the time trend of the maximum temperature from 1980 to 1987 is $y=0.0351 x+13.9582$. The linear fitting equation of the time trend of the lowest temperature from 1980 to 1987 is $y=-0.1069 x+$ 6.7736. The linear fitting equation of the time change trend of the average temperature from 1980 to 1987 is $y=-0.0351 x+10.3843$. It can be seen that with the progress of time, the annual maximum temperature will be higher and lower, while the annual minimum temperature will be lower and lower. In general, the annual average temperature is slowly decreasing.

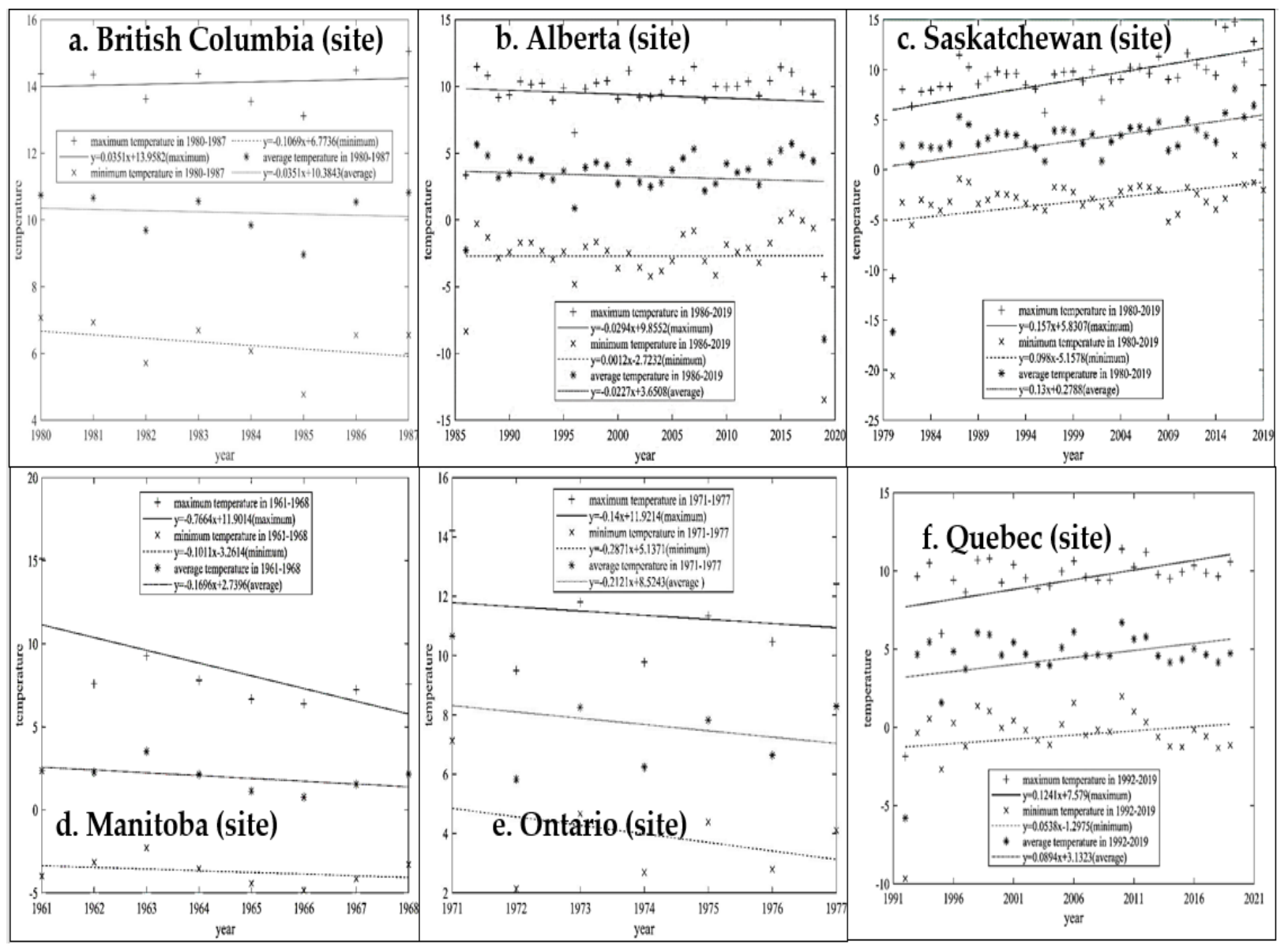

Figure 3. Scatter plot and linear fit plot. Where, (a). denotes British Colombia, (b). Alberta, (c). Saskatchewan, (d). Manitoba, (e). Ontario and (f). Quebec.

It can be concluded from Figure $3 b$ that the linear fitting equation of the time variation trend of maximum temperature in Alberta from 1986 to 2019 is $y=-0.0294 x+9.8552$. The linear fitting equation of the time variation trend of the minimum temperature from 1986 to 2019 is $y=0.0012 x-2.7232$. The linear fitting equation of the time variation trend of average temperature from 1986 to 2019 is as follows: $y=-0.0227 x+3.6508$. It can be seen that with the progress of time, the annual maximum temperature will be lower and lower, and the annual minimum temperature is slowly rising, but overall, the annual average temperature is also slowly decreasing.

It can be concluded from Figure $3 c$ that the linear fitting equation of the time change trend of the maximum temperature in Saskatchewan from 1980 to 2019 is $y=0.157 x+$ 5.8307. The linear fitting equation of the time variation trend of the minimum temperature from 1980 to 2019 is $y=0.098 x-5.1578$. The linear fitting equation of the time variation trend of average temperature from 1980 to 2019 is as follows: $y=0.13 x+0.2788$. It can be seen that as time goes on, the annual maximum temperature will get higher and higher, and 
the annual minimum temperature will also get higher and higher. In general, the annual average temperature will also increase.

It can be concluded from Figure $3 d$ that the linear fitting equation of the time change trend of the maximum temperature in Manitoba during 1961-1968 is $y=-0.7664 x+$ 11.9014. The linear fitting equation of the time variation trend of the minimum temperature during 1961-1968 is $\mathrm{y}=-0.1011 \mathrm{x}-3.2614$. The linear fitting equation of the time variation trend of average temperature during $1961-1968$ is $y=-0.1696 x+2.7396$. It can be seen that as time goes on, the annual maximum temperature will get lower and lower, and the annual minimum temperature will also get lower and lower. In general, the annual average temperature will also decrease.

It can be concluded from Figure $3 e$ that the linear fitting equation of the time change trend of the maximum temperature in Ontario from 1971 to 1977 is $\mathrm{y}=-0.14 \mathrm{x}+11.9214$. The linear fitting equation of the time variation trend of the minimum temperature from 1971 to 1977 is $y=-0.2871 x+5.1371$. The linear fitting equation of the time variation trend of average temperature from 1971 to 1977 is $y=-0.2121 x+8.5243$. It can be seen that as time goes on, the annual maximum temperature will get lower and lower, and the annual minimum temperature will also get lower and lower. In general, the annual average temperature will also decrease.

From Figure 3f, it can be concluded that the linear fitting equation of the time change trend of the maximum temperature in Quebec from 1992 to 2019 is $y=0.1241 x+7.579$. The linear fitting equation of the time variation trend of the minimum temperature from 1992 to 2019 is $y=0.0538 x-1.2975$. The linear fitting equation of the time variation trend of average temperature from 1992 to 2019 is as follows: $y=0.0894 x+3.1323$. It can be seen that as time goes on, the annual maximum temperature will get higher and higher, and the annual minimum temperature will also get higher and higher. In general, the annual average temperature will also increase.

\subsection{The Relationship between the Occurrence of Extreme Weather and Climate Change}

In order to analyze whether the emergence of extreme weather is related to climate change, the study takes two provinces as an example (Alberta (site: 1986-2019) and Saskatchewan (Site: 1980-2019)). We consider the completeness of the data period along with Pearson correlation analysis on extreme weather (such as data on the daily minimum temperature and daily snowfall of "extreme cold weather") and climate change (such as data on annual average temperature and annual snowfall). Specifically, it analyses the correlation between the seven variables: (i) daily maximum temperature of the year (DMAT), (ii) daily minimum temperature of the year (DMIT), (iii) annual maximum temperature, which weighted average daily data (AMAT), (iv) annual minimum temperature, which weighted average daily data (AMIT), (v) annual average temperature which weighted average of daily data (AAT), (vi) the most extensive daily rainfall during the year (TALR), and (vii) the highest daily snowfall during the year (THDS). Pearson correlation analysis is shown in Tables 5 and 6:

Table 5. Pearson correlation analysis of extreme weather and climate change for Alberta.

\begin{tabular}{|c|c|c|c|c|c|c|c|}
\hline & DMAT & DMIT & AMAT & AMIT & AAT & TALR & THDS \\
\hline DMAT & 1 & $\begin{array}{l}-0.080 \\
(0.654)\end{array}$ & $0.865^{* *}(0.000)$ & $0.810 * *(0.000)$ & $0.842 * *(0.000)$ & $0.312(0.073)$ & $0.410 *(0.016)$ \\
\hline $\begin{array}{l}\text { DMIT } \\
\text { AMAT } \\
\text { AMIT } \\
\text { AAT } \\
\text { TALR } \\
\text { THDS }\end{array}$ & & 1 & $\begin{array}{c}0.044(0.804) \\
1\end{array}$ & $\begin{array}{c}0.070(0.694) \\
0.929 * *(0.000) \\
1\end{array}$ & $\begin{array}{c}0.059(0.738) \\
0.979^{* *}(0.000) \\
0.978^{* *}(0.000) \\
1\end{array}$ & $\begin{array}{c}-0.074(0.678) \\
0.431 *(0.011) \\
0.439 *(0.009) \\
0.461(0.006) \\
1\end{array}$ & $\begin{array}{c}-0.166(0.348) \\
0.099(0.576) \\
0.129(0.466) \\
0.118(0.506) \\
-0.104(0.558) \\
1\end{array}$ \\
\hline
\end{tabular}

Note: ${ }^{* *}$ means significant at 0.01 levels (bilateral), ${ }^{*}$ means significant at 0.05 levels (bilateral). 
Table 6. Pearson correlation analysis of extreme weather and climate change for Saskatchewan.

\begin{tabular}{cccccccc}
\hline & DMAT & DMIT & AMAT & AMIT & AAT & TALR & THDS \\
\hline DMAT & 1 & $0.094(0.564)$ & $0.822^{* *}(0.000)$ & $0.818^{* *}(0.000)$ & $0.832 * *(0.000)$ & $0.310(0.052)$ & $0.182(0.261)$ \\
DMIT & & 1 & $0.175(0.279)$ & $0.123(0.449)$ & $0.161(0.321)$ & $-0.173(0.285)$ & $-0.203(0.208)$ \\
AMAT & & & 1 & $0.941^{* *}(0.000)$ & $0.988^{* *}(0.000)$ & $0.245(0.128)$ & $0.135(0.576)$ \\
AMIT & & & & & $0.977^{* *}(0.000)$ & $0.241(0.135)$ & $0.071(0.665)$ \\
AAT & & & & & & $0.249(0.122)$ & $0.112(0.493)$ \\
TALR & & & & & & 1 & $0.177(0.273)$ \\
THDS & & & & & & 1 \\
\hline
\end{tabular}

Note: ${ }^{* *}$ means significant at 0.01 level (bilateral).

According to Table 5, Alberta (1986-2019) has a significant positive correlation between the DMAT and AMAT, AMIT, and AAT. The correlation coefficients are $0.865,0.810$, and 0.842 (all significant at the 0.01 level (two-sided)), and they are all greater than 0.8 . This shows that the emergence of extreme weather (extreme heat) is closely related to climate change. The TALR is also significantly positively correlated with the AMAT and AMIT. The correlation coefficients has found 0.431 (significant at the 0.05 level (bilateral)) and 0.439 (significant at the 0.01 level (bilateral)). Moreover, it is between 0.3 and 0.5 . The low degree of positive correlation indicates the higher TALR, the higher AMAT, and AMIT. The occurrence of such extreme weather is more related to climate change. At the same time, there is also a strong correlation between extreme weather and climate change. For example, there is a positive correlation between DMAT and THDS (the correlation coefficient is 0.410 , significant at the 0.05 level (both sides)). There is a positive correlation between AMAT and AMIT, AAT (correlation coefficients are 0.929 and 0.979 respectively, and both are significant at the 0.01 level (two-sided)). We found a highly positive correlation between the AMIT and AAT \{correlation coefficient is 0.978 , at the 0.01 level (two-sided) significantly\}.

According to Table 6, Saskatchewan (1980-2019) has a significant positive correlation between DMAT and AMAT, AMIT, and AAT. The correlation coefficients are 0.822, 0.818, and 0.832 , respectively (all are significant at the 0.01 level (two-sided)), and greater than 0.8 . The high positive correlation between variables indicates that extreme weather (extreme heat) is closely related to climate change. At the same time, there is also a strong correlation between climate change and other variables. For example, the AMAT is highly positively correlated with the AMIT and the AAT (correlation coefficients are 0.941 and 0.988 respectively, and both are significant at the level of 0.01 (both sides)). The AMIT and the AAT are highly positive correlations (correlation coefficient of 0.977 , significant at the 0.01 level (two-sided)).

\subsection{Contradiction Analysis of Global Warming and Extreme Cold in Local Areas}

(i) As shown in Figure 4, the horizontal axis represents the time of evolution, and the vertical axis represents the probability of global warming and extreme local cold. As global warming and local cold occur when the initial probability is not high $(<0.5)$, with time, global warming and the probability of local cold will be lower and lower until it tends to zero. The smaller the initial probability value, the faster the trend to zero. On the contrary, global warming and local cold occur when the initial probability is not high (>0.7). As time goes on, the probability of global warming and extreme local cold will increase until it approaches 1 . As the initial probability value is relatively higher, the speed of the approach to 1 will be faster. This shows that when both global warming and local extreme cold phenomenon appear, we should pay attention to them, find out the internal factors from the source, and solve them in time to curb the trend of worsening. 


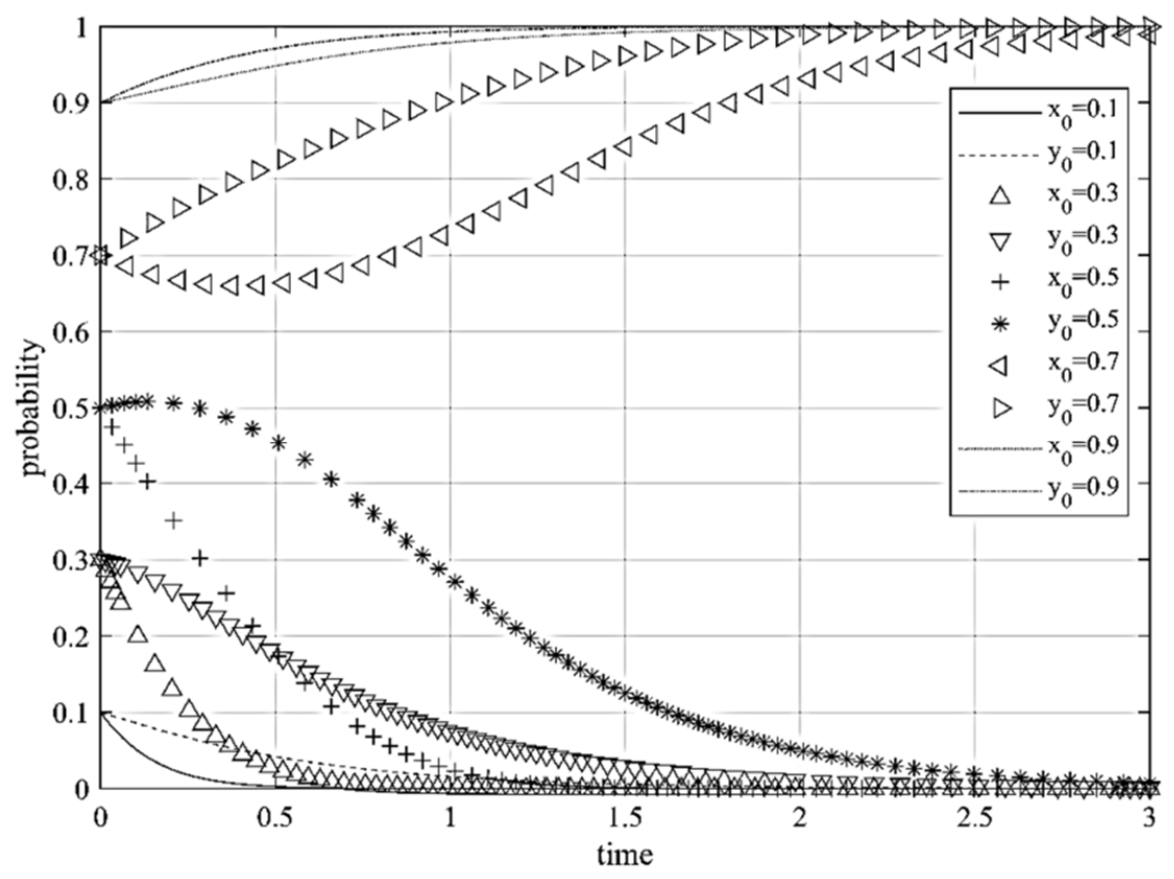

Figure 4. Evolution paths of global warming and local extreme cold game with different initial probability values.

(ii) Figure 5 denotes the evolution paths of global warming and extreme local cold at different times given parameter values. As shown in Figure 5, the smaller the contribution (a) made by the extreme local cold to alleviating the global warming trend, the lower the probability of global warming. When $a$ is smaller or larger, the probability of global warming will also faster tend to 0 or 1 . Furthermore, there is a demarcation point between 10 to 15 , so the probability of global warming tends to a stable value.

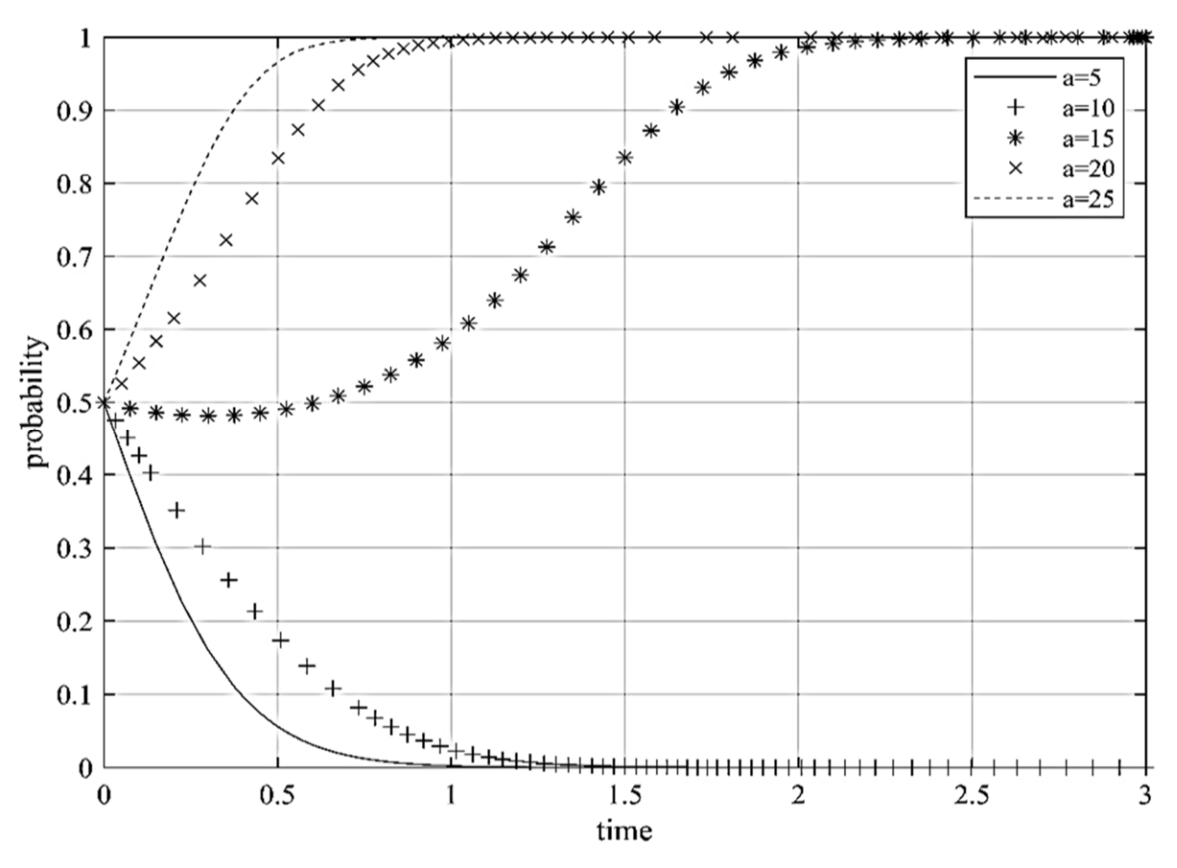

Figure 5. Evolution path of global warming with different parameter values. 
As shown in Figure 6, the smaller the contribution $\boldsymbol{b}$ made by the extreme local cold to alleviate the global warming trend, the lower the probability of global warming. Seemingly, the greater the $\boldsymbol{b}$ value, the greater the probability of global warming will be. When $\boldsymbol{b}$ is smaller or larger, the probability of global warming will also more quickly tend to 0 or 1 . Furthermore, there is a demarcation point between $\boldsymbol{b}$ found 10 to 15 , so the probability of global warming tends to a stable value.

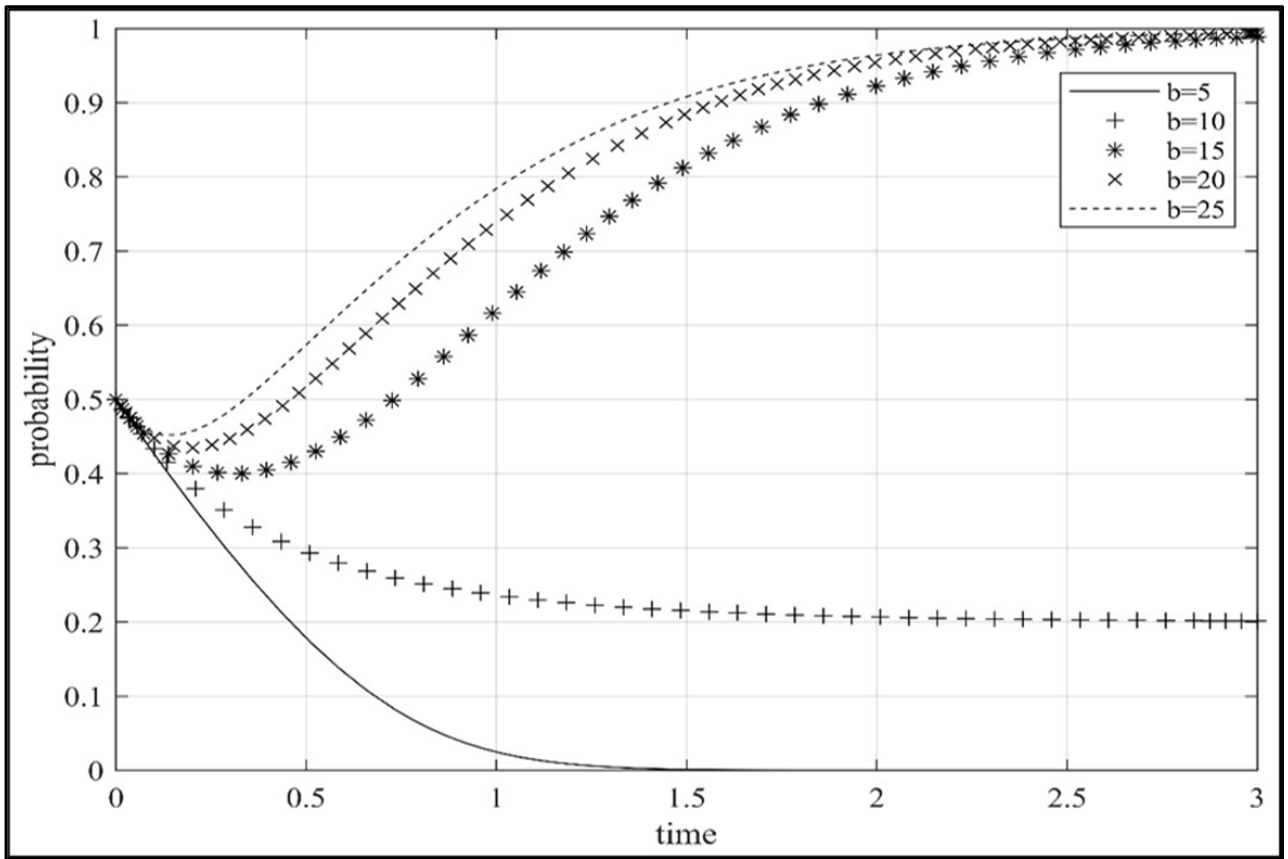

Figure 6. Evolution path of polar cold at different times with a given parameter value.

From the above analysis, it can be seen that global warming and extreme local cold are not contradictory. Through evolutionary game analysis, it is found that there is a certain degree of synchronization between the two under certain conditions, interacting and affecting each other. The trend of global warming cannot be denied just because of the local extreme cold weather. Climate change is a long-term, gradual, and predictable trend, while the weather is short-term, local, unstable, and unpredictable [34]. Weather is usually a short-term process ranging from a few minutes to a few days. It refers to the instantaneous or short-term atmospheric conditions in a specific area, such as cloudy, sunny, rainy, and snowy [35]. At the same time, climate change refers to long-term changes. Although it also refers to atmospheric phenomena, it is the average condition over many years. It is usually reflected by the characteristic values of temperature, precipitation, wind, sunshine, humidity, and other climatic elements recorded by meteorological observation equipment [36]. The World Meteorological Organization defines climate change as referring to changes on this scale over a period of 30 years.

\section{Discussion}

The logical framework of this study is as follows: first, the study establishes a time series of extreme temperature values based on data from weather stations in six provinces in Canada, analyzes changes in time and space, and studies the effect of ocean temperature on land temperature. Second, taking Alberta and Saskatchewan as examples, the Pearson correlation analysis of extreme weather and climate change in the two provinces is carried out. Finally, the evolutionary game method discusses the relationship between global warming and extreme local cold. Before discussing the linear fitting equation of the time change trend of each province, the relationship between the two variables of time and temperature can be represented by a straight line through the scatter plot. As the reviewers 
said, due to the difficulty of data collection, the period in some provinces is less than ten years. However, because of the correlation between Canadian climate change and time, the two variables studied in this article do not involve climate prediction. Rather, the primary purpose is to use existing statistical data to establish simplified climate models and extreme weather models. The prime aim of the study is to explore the available data so that non-professional people understand the global climate change situation, explain the occurrence of extreme weather phenomena, and verify the factors that affect climate change, thereby enhancing people's awareness of climate change. Therefore, this article adopts this most basic regression analysis method to illustrate the results.

From a global perspective, the warming trend continues, leading to rising sea levels flooding coastal areas, floods, droughts, and other extreme weather events, deeply endangering the global environment [37]. The outcome assists us to lay out the main foundations of the study. The concept of global climate warming can embody global warming and sea surface temperature rising [38]. Although some countries and regions have extremely cold weather in a short period, this does not represent the global climate environment [39]. Many scientists (such as Gjermundsen et al. [40], Lashof and Ahuja [41], and Swart et al. [42]) believe that the aggravation of the greenhouse effect caused by the massive emission of greenhouse gases may be the root cause of global warming, with the most significant increase in greenhouse gas being carbon dioxide. The current study also shows a sharp alternation of temperature within the studied areas. Carbon dioxide (CO2) is the primary greenhouse gas emitted through human activities [43-46].

The study found that the impact of global warming on high latitudes is apparent and one of the primary reasons for the "El Niño" phenomenon, which is consistent with the existing literature (such as Iyer et al. [47], and Yang et al. [48]). In a study of northern British Columbia, Friesen et al. [49] found that ocean currents have a reconciling effect when extreme weather occurs, making the annual temperature change only within a small range. The seawater temperature change is consistent with surface temperature change, which is similar to our study. We also found that as human excessive production behavior and industrialization in recent years have increased substantially, local extreme weather is an occasional weather change, with a certain degree of randomness. The outcome is consistent with the study of DeFrancesco and Guéguen [50]. According to Wang et al. [51], global warming and the local extreme cold phenomenon have a certain degree of synchronization. Seemingly, under certain conditions, the probability of both occurrences will tend to 0 or 1 , and a stable state will be formed as time progresses, which is similar to our study's findings.

Among these findings, 1980-1984 was the hottest five year period. However, the warming momentum has not weakened so far. Since the Industrial Revolution, human activities have intensified due to the rapid growth of the world's population. With the population surge, urbanization, industrialization, and transportation modernization process accelerated, many natural resources such as forests and minerals have been consumed, resulting in a sharp decline in the global forest area [52-54].

\section{Conclusions}

Taking six representative provinces of Canada as an example, the study uses the percentile method to define the high value of the maximum temperature and the low value of the minimum temperature of different stations year by year. It analyses its spatial variation characteristics and spatio-temporal variation trend through the multiple linear regression linear fitting method. Moreover, the Pearson correlation analysis has been used to study the relationship between extreme weather and climate change occurrence. The evolutionary game method and MATLAB software have been used to draw dynamic phase maps and numerical simulations of evolution paths. The main findings of the study are:

(i) The frequency of extreme weather in Canada is relatively high. As time progresses in most regions, the annual maximum temperature will increase continuously, and the average temperature will also rise every year. The annual minimum temperature will also be higher. The impact of global warming on high latitudes is becoming more and 
more apparent, which can curb the occurrence of the "El Niño" phenomenon. Surface temperatures face a reconciling effect when extreme weather occurs, making the annual temperature change occur only within a small range. The change in seawater temperature is consistent with the change in surface temperature. In terms of regional circumstances, the maximum and minimum temperatures in British Columbia (site) and Alberta (site) have risen, but the average temperature has shown a downward trend, while in Saskatchewan (site) and Quebec (site) they on the rise; and in Manitoba (site) and Ontario (site) they are on the decline.

(ii) The maximum daily temperature (extreme precipitation) during the year is significantly positively correlated with the annual maximum, minimum, and annual average temperature (climate change). The maximum daily precipitation (extreme precipitation) during the year is positively correlated with the annual maximum and minimum temperature (climate change), considering that global warming is the catastrophic result of excessive human production behavior and industrialization in recent years. At the same time, the extreme local cold is an occasional weather change with a certain degree of randomness.

(iii) The emergence of global warming and the local extreme cold phenomenon has a certain degree of synchronization. Under certain conditions, the probability of both occurrences will tend to 0 or 1 , and a stable state will be formed as time progresses.

(iv) Global warming is not inconsistent with the existence of extreme weather in a specific place, and the trend of global warming cannot be denied because of local extreme cold weather. The primary countermeasure against global warming is to reduce carbon dioxide emissions. By analyzing the temporal and spatial trends of climate warming in Canada, we suggest that countries worldwide should actively cooperate with multilateral organizations dealing with climate change and work together to reach a consensus on emissions reduction. Developed countries should take the initiative to help less developed countries promote the development of renewable energy and energy-saving technologies, improve energy structure, and improve efficiency. The article is limited in the following aspects. The research area only selects six provinces in Canada; not all provinces are involved, and the scope of selection of meteorological observation points is relatively small. Future research should further increase the number of research observation points and strive to involve all regions of Canada. Due to the difficulty of data collection, the collection time range of different meteorological observation points cannot be kept consistent, which leads to some limitations in this study. Data range limited to fewer than 10 years could have produced biased results for climatological analysis. A more mature data set should be implemented for crafting more robust data. The potential study should continue to supplement the meteorological observation data across Canada and use the evolutionary game theory to construct a tripartite evolutionary game model that comprehensively discusses the relationship between the emergence of extreme weather and climate change. Future studies should analyze the simulation results of the six climate models, including crucial factors such as the earth's heat absorption, heat dissipation, and ocean temperature. The key suggested methods for simulating climate models currently include the general circulation model (GCM), global coupled atmospheric-oceanic circulation model (CGCM), energy balance model, radioactive and convective model, directional average dynamic mode, and stochastic statistical dynamic model.

Author Contributions: Conceptualization, Yameng Wang, Apurbo Sarkar and Feng Wei; methodology, Yameng Wang, Md. Shakhawat Hossain and Apurbo Sarkar; software, Md. Shakhawat Hossain and Yingdong Tian; validation, Ahmed Khairul Hasan and Md. Shakhawat Hossain; formal analysis, Yameng Wang and Apurbo Sarkar; investigation, Yameng Wang and Apurbo Sarkar; resources, Qian $\mathrm{Wu}$, Yingdong Tian and Ahmed Khairul Hasan; data curation, Qian Wu, Apurbo Sarkar and Yameng Wang; writing — original draft preparation, Yameng Wang and Apurbo Sarkar; writing-review and editing, Yameng Wang, Feng Wei, Ahmed Khairul Hasan and Apurbo Sarkar; visualization, Md. Shakhawat Hossain and Yingdong Tian; supervision, Feng Wei and Qian Wu; project administration, Feng Wei and Yingdong Tian; funding acquisition, Feng Wei All authors have read and agreed to the published version of the manuscript. 
Funding: This research was funded by (i) the National Natural Science Foundation of China, grant numbers 71673222 and 72064009. (ii) Humanities and Social Science Fund of Ministry of Education of China, grant number 15XJA790005. (iii) The Shaanxi Provincial Key R\&D Program Project, grant number 2020KW-029. (iv) China Scholarship Council Funded Project, grant number 202106300001. (v) General Project of Shanghai Cooperation Institute for Modern Agricultural Development "Food Issues in SCO Countries" (SCO21A002).

Institutional Review Board Statement: This study mainly focused on models and data analysis and did not involve human factors considered dangerous. Therefore, ethical review and approval were waived for this study.

\section{Informed Consent Statement: Not applicable.}

Data Availability Statement: Data are available on request due to restrictions, e.g., privacy or ethics. The data presented in this study are available on request from the corresponding author. The data are not publicly available due to the strict management of various data and technical resources within the research teams.

Acknowledgments: We would like to thank the journal experts who edited this paper. We also appreciate the constructive suggestions and comments on the manuscript from the reviewer(s) and editor(s).

Conflicts of Interest: The authors declare no conflict of interest.

Disclosure Statement: The authors report no potential conflict of interest.

\section{References}

1. Lesk, C.; Rowhani, P.; Ramankutty, N. Influence of Extreme Weather Disasters on Global Crop Production. Nature 2016, 529, 84-87. [CrossRef] [PubMed]

2. Elahi, E.; Khalid, Z.; Tauni, M.Z.; Zhang, H.; Lirong, X. Extreme Weather Events Risk to Crop-Production and the Adaptation of Innovative Management Strategies to Mitigate the Risk: A Retrospective Survey of Rural Punjab, Pakistan. Technovation 2021, 102255. [CrossRef]

3. Mirza, M.M.Q. Climate Change and Extreme Weather Events: Can Developing Countries Adapt? Clim. Policy 2003, 3, 233-248. [CrossRef]

4. Allard, R.F. Climate Change Adaptation: Infrastructure and Extreme Weather. In Industry, Innovation and Infrastructure; Leal Filho, W., Azul, A.M., Brandli, L., Lange Salvia, A., Wall, T., Eds.; Springer International Publishing: Cham, Switzerland, 2021; pp. 105-116. ISBN 978-3-319-95873-6.

5. Barbieri, M.; Barberio, M.D.; Banzato, F.; Billi, A.; Boschetti, T.; Franchini, S.; Gori, F.; Petitta, M. Climate Change and Its Effect on Groundwater Quality. Environ. Geochem. Health 2021, 1-12. [CrossRef]

6. Dixit, A.; Sahany, S.; Kulkarni, A.V. Glacial Changes over the Himalayan Beas Basin under Global Warming. J. Environ. Manag. 2021, 295, 113101. [CrossRef]

7. Geiger, T.; Gütschow, J.; Bresch, D.N.; Emanuel, K.; Frieler, K. Double Benefit of Limiting Global Warming for Tropical Cyclone Exposure. Nat. Clim. Chang. 2021, 11, 861-866. [CrossRef]

8. Robertson, S. Transparency, Trust, and Integrated Assessment Models: An Ethical Consideration for the Intergovernmental Panel on Climate Change. WIREs Clim. Chang. 2021, 12, e679. [CrossRef]

9. IPCC. Special Report on Global Warming of $1.5^{\circ} \mathrm{C}$; Cambridge University Press: Cambridge, UK, 2018.

10. Liu, X.; Yuan, X.; Zhu, E. Global Warming Induces Significant Changes in the Fraction of Stored Precipitation in the Surface Soil. Glob. Planet. Chang. 2021, 205, 103616. [CrossRef]

11. Lasagna, M.; Ducci, D.; Sellerino, M.; Mancini, S.; De Luca, D.A. Meteorological Variability and Groundwater Quality: Examples in Different Hydrogeological Settings. Water 2020, 12, 1297. [CrossRef]

12. Wang, Q.; Lu, M.; Bai, Z.; Wang, K. Coronavirus Pandemic Reduced China's CO2 Emissions in Short-Term, While Stimulus Packages May Lead to Emissions Growth in Medium- and Long-Term. Appl. Energy 2020, 278, 115735. [CrossRef]

13. Mason, B.J. The Greenhouse Effect. Contemp. Phys. 1989, 30, 417-432. [CrossRef]

14. Boyes, E.; Stanisstreet, M. The 'Greenhouse Effect': Children's Perceptions of Causes, Consequences and Cures. Int. J. Sci. Educ. 1993, 15, 531-552. [CrossRef]

15. Withey, P.; Johnston, C.; Guo, J. Quantifying the Global Warming Potential of Carbon Dioxide Emissions from Bioenergy with Carbon Capture and Storage. Renew. Sustain. Energy Rev. 2019, 115, 109408. [CrossRef]

16. Lyu, K.; Zhang, X.; Church, J.A. Projected Ocean Warming Constrained by the Ocean Observational Record. Nat. Clim. Chang. 2021, 11, 834-839. [CrossRef]

17. Li, Y.; Li, Z.; Zhang, Z.; Chen, L.; Kurkute, S.; Scaff, L.; Pan, X. High-Resolution Regional Climate Modeling and Projection over Western Canada Using a Weather Research Forecasting Model with a Pseudo-Global Warming Approach. Hydrol. Earth Syst. Sci. 2019, 23, 4635-4659. [CrossRef] 
18. Yanni, S.F.; Laporte, A.D.; Rajsic, P.; Wagner-Riddle, C.; Weersink, A. The Environmental and Economic Efficacy of On-Farm Beneficial Management Practices for Mitigating Soil-Related Greenhouse Gas Emissions in Ontario, Canada. Renew. Agric. Food Syst. 2021, 36, 307-320. [CrossRef]

19. St. Denis, G.; Parker, P. Community Energy Planning in Canada: The Role of Renewable Energy. Renew. Sustain. Energy Rev. 2009, 13, 2088-2095. [CrossRef]

20. Belley, P.M.; Groat, L.A. Metamorphosed Carbonate Platforms and Controls on the Genesis of Sapphire, Gem Spinel, and Lapis Lazuli: Insight from the Lake Harbour Group, Nunavut, Canada and Implications for Gem Exploration. Ore Geol. Rev. 2020, 116, 103259. [CrossRef]

21. Ye, D.; Yan, Z.; Dai, X.; Qian, W.; Ye, Q. Future Weather and Climate Prediction System. Meteorology 2006, 3, 3-8.

22. Guo, Q.; Cai, J.; Shao, X.; Sha, W. The Influence of the Interdecadal Variability of the East Asian Summer Monsoon on the Climate in China. Acta Geogr. Sin. 2003, 58, 569-576.

23. Nakamura, H. Year-to-Year and Interdecadal Variability in the Activity of Intraseasonal Fluctuations in the Northern Hemisphere Wintertime Circulation. Theor. Appl. Climatol. 1996, 55, 19-32. [CrossRef]

24. Nakamura, H.; Yamagata, T. Recent Decadal SST Variability in the Northwestern Pacific and Associated Atmospheric Anomalies. In Beyond El Niño; Navarra, A., Ed.; Springer: Berlin/Heidelberg, Germany, 1999; pp. 49-72. ISBN 978-3-642-63556-4.

25. Weaver, A.J.; Sarachik, E.S.; Marotze, J. Freshwater Flux Forcing of Decadal and Interdecadal Oceanic Variability. Nature 1991, 353, 836-838. [CrossRef]

26. Latif, M.; Barnett, T.P. Causes of Decadal Climate Variability over the North Pacific and North America. Science 1994, $266,634-637$. [CrossRef] [PubMed]

27. Smith, H.J. CLIMATE SCIENCE: Eye of the Beholder. Science 2007, 315, 1467e-1469e. [CrossRef]

28. Hawkins, D.; Peridas, G.; Steelman, J. Twelve Years after Sleipner: Moving CCS from Hype to Pipe. Energy Procedia 2009, 1, 4403-4410. [CrossRef]

29. Ezekiel, M. Methods of Correlation Analysis; Wiley: Oxford, UK, 1930.

30. Zou, Y.; Zhang, Y.; Cheng, K. Exploring the Impact of Climate and Extreme Weather on Fatal Traffic Accidents. Sustainability 2021, 13, 390. [CrossRef]

31. Qiao, W.; Yin, X. Understanding the Impact on Energy Transition of Consumer Behavior and Enterprise Decisions through Evolutionary Game Analysis. Sustain. Prod. Consum. 2021, 28, 231-240. [CrossRef]

32. Xu, L.; Di, Z.; Chen, J. Evolutionary Game of Inland Shipping Pollution Control under Government Co-Supervision. Mar. Pollut. Bull. 2021, 171, 112730. [CrossRef]

33. Weibull, J.W. Evolutionary Game Theory; MIT Press: Cambridge, MA, USA, 1995; ISBN 978-0-262-23181-7.

34. Tol, R.S.J. The Economic Effects of Climate Change. J. Econ. Perspect. 2009, 23, 29-51. [CrossRef]

35. Jiang, T.; Su, B.; Hartmann, H. Temporal and Spatial Trends of Precipitation and River Flow in the Yangtze River Basin, 1961-2000. Geomorphology 2007, 85, 143-154. [CrossRef]

36. Dai, A. Increasing Drought under Global Warming in Observations and Models. Nat. Clim. Chang. 2013, 3, 52-58. [CrossRef]

37. Xie, S.-P.; Deser, C.; Vecchi, G.A.; Ma, J.; Teng, H.; Wittenberg, A.T. Global Warming Pattern Formation: Sea Surface Temperature and Rainfall. J. Clim. 2010, 23, 966-986. [CrossRef]

38. Watanabe, M.; Dufresne, J.-L.; Kosaka, Y.; Mauritsen, T.; Tatebe, H. Enhanced Warming Constrained by Past Trends in Equatorial Pacific Sea Surface Temperature Gradient. Nat. Clim. Chang. 2021, 11, 33-37. [CrossRef]

39. Amos, C.L.; Martino, S.; Sutherland, T.F.; Al Rashidi, T. Sea Surface Temperature Trends in the Coastal Zone of British Columbia, Canada. J. Coast. Res. 2014, 31, 434-446. [CrossRef]

40. Gjermundsen, A.; Nummelin, A.; Olivié, D.; Bentsen, M.; Seland, Ø.; Schulz, M. Shutdown of Southern Ocean Convection Controls Long-Term Greenhouse Gas-Induced Warming. Nat. Geosci. 2021, 14, 724-731. [CrossRef]

41. Lashof, D.A.; Ahuja, D.R. Relative Contributions of Greenhouse Gas Emissions to Global Warming. Nature 1990, 344, 529-531. [CrossRef]

42. Swart, N.C.; Gille, S.T.; Fyfe, J.C.; Gillett, N.P. Recent Southern Ocean Warming and Freshening Driven by Greenhouse Gas Emissions and Ozone Depletion. Nat. Geosci. 2018, 11, 836-841. [CrossRef]

43. Silvy, Y.; Guilyardi, E.; Sallée, J.-B.; Durack, P.J. Human-Induced Changes to the Global Ocean Water Masses and Their Time of Emergence. Nat. Clim. Chang. 2020, 10, 1030-1036. [CrossRef]

44. Marlon, J.R.; Bartlein, P.J.; Carcaillet, C.; Gavin, D.G.; Harrison, S.P.; Higuera, P.E.; Joos, F.; Power, M.J.; Prentice, I.C. Climate and Human Influences on Global Biomass Burning over the Past Two Millennia. Nat. Geosci. 2008, 1, 697-702. [CrossRef]

45. Gillett, N.P.; Stone, D.A.; Stott, P.A.; Nozawa, T.; Karpechko, A.Y.; Hegerl, G.C.; Wehner, M.F.; Jones, P.D. Attribution of Polar Warming to Human Influence. Nat. Geosci. 2008, 1, 750-754. [CrossRef]

46. Gillett, N.P.; Kirchmeier-Young, M.; Ribes, A.; Shiogama, H.; Hegerl, G.C.; Knutti, R.; Gastineau, G.; John, J.G.; Li, L.; Nazarenko, L.; et al. Constraining Human Contributions to Observed Warming since the Pre-Industrial Period. Nat. Clim. Chang. 2021, 11, 207-212. [CrossRef]

47. Iyer, V.; Sharma, A.; Nair, D.; Solanki, B.; Umrigar, P.; Murtugudde, R.; Jiang, C.; Mavalankar, D.; Sapkota, A. Role of Extreme Weather Events and El Niño Southern Oscillation on Incidence of Enteric Fever in Ahmedabad and Surat, Gujarat, India. Environ. Res. 2021, 196, 110417. [CrossRef] 
48. Yang, Y.; Gan, T.Y.; Tan, X. Recent Changing Characteristics of Dry and Wet Spells in Canada. Clim. Chang. 2021, 165, 42. [CrossRef]

49. Friesen, S.K.; Rubidge, E.; Martone, R.; Hunter, K.L.; Peña, M.A.; Ban, N.C. Effects of Changing Ocean Temperatures on Ecological Connectivity among Marine Protected Areas in Northern British Columbia. Ocean Coast. Manag. 2021, 211, 105776. [CrossRef]

50. DeFrancesco, C.; Guéguen, C. Long-Term Trends in Dissolved Organic Matter Composition and Its Relation to Sea Ice in the Canada Basin, Arctic Ocean (2007-2017). J. Geophys. Res. Oceans 2021, 126, e2020JC016578. [CrossRef]

51. Wang, X.; Thompson, D.K.; Marshall, G.A.; Tymstra, C.; Carr, R.; Flannigan, M.D. Increasing Frequency of Extreme Fire Weather in Canada with Climate Change. Clim. Chang. 2015, 130, 573-586. [CrossRef]

52. Brito-Morales, I.; Schoeman, D.S.; Molinos, J.G.; Burrows, M.T.; Klein, C.J.; Arafeh-Dalmau, N.; Kaschner, K.; Garilao, C.; Kesner-Reyes, K.; Richardson, A.J. Climate Velocity Reveals Increasing Exposure of Deep-Ocean Biodiversity to Future Warming. Nat. Clim. Chang. 2020, 10, 576-581. [CrossRef]

53. Ding, D.; Maibach, E.W.; Zhao, X.; Roser-Renouf, C.; Leiserowitz, A. Support for Climate Policy and Societal Action Are Linked to Perceptions about Scientific Agreement. Nat. Clim. Chang. 2011, 1, 462-466. [CrossRef]

54. Overland, J.E.; Wood, K.R.; Wang, M. Warm Arctic-Cold Continents: Climate Impacts of the Newly Open Arctic Sea. Polar Res. 2011, 30, 15787. [CrossRef] 